\title{
Improved Propulsion Motor Design for a Twelve Passenger All-Electric Aircraft
}

\author{
Ahmed Hebala \\ Power Electronics, Machines and Control \\ (PEMC) Research Group, Faculty of \\ Engineering \\ University of Nottingham \\ Nottingham, United Kingdom \\ ahmed.hebala@nottingham.ac.uk \\ Paolo Giangrande \\ Power Electronics, Machines and Control \\ (PEMC) Research Group, Faculty of \\ Engineering \\ University of Nottingham \\ Nottingham, United Kingdom \\ paolo.giangrande@nottingham.ac.uk
}

\author{
Stefano Nuzzo \\ Department of Engineering Enzo \\ Ferrari \\ University of Modena and Reggio \\ Emilia \\ Modena, Italy \\ stefano.nuzzo@unimore.it \\ Chris Gerada \\ Power Electronics, Machines and Control \\ (PEMC) Research Group, Faculty of \\ Engineering \\ University of Nottingham \\ Nottingham, United Kingdom \\ chris.gerada@nottingham.ac.uk
}

\author{
Peter H. Connor \\ Power Electronics, Machines and Control \\ (PEMC) Research Group, Faculty of \\ Engineering \\ University of Nottingham \\ Nottingham, United Kingdom \\ peter.connor@nottingham.ac.uk \\ Michael Galea \\ Key Laboratory of More Electric Aircraft \\ Technology of Zhejiang Province \\ University of Nottingham \\ Ningbo, China \\ michael.galea@nottingham.ac.uk
}

\begin{abstract}
$1 \square$ Abstract - This paper investigates the design of a 12-seater aircraft electric propulsion motor (ProMo). The design procedures aim to improve the performance of a previously designed motor, while adding further restrictions to the electrical and thermal boundaries. The main targets are to achieve the required output power of $550 \mathrm{~kW}$, low torque ripple and an efficiency higher than 97\%. The proposed procedures include an optimum slot/pole combination study, investigation on the winding configuration and connection, scaling of the airgap thickness and permanent magnet (PM) thicknesses, and finally minimising of the motor volume. The electromagnetic design is performed through a finite element electromagnetic software package, whereas the thermal analysis uses a lumped parameter thermal network-based. The mechanical stress above the rated speed of $2000 \mathrm{rpm}$ is also examined. The final design fulfils the design requirements and meets the electrical and thermal constraints.
\end{abstract}

Index Terms-- All-Electric Aircraft (AEA), Aircraft propulsion, Electrification, Finite Element Analysis (FEA), Machine design, More Electric Aircraft (MEA), Permanent Magnet Synchronous Motor (PMSM), Winding configuration.

\section{INTRODUCTION}

$\mathrm{T}$ HE ever-growing demand and specifications for safer, cleaner, and quieter air travel push industry and academia alike in the field of electrified aircraft. The electrification of commercial aviation would demonstrate a technological leap for the aircraft industry. More electric aircraft (MEA) and allelectric aircraft (AEA) both serve as ambitious challenges. Development of electrified aircraft propulsion comes at the heart of this challenge, as it seeks to improve the most energy consuming and most polluting operation, to provide safe, clean and reliable travel [1], [2]. Therefore, the design of an electric propulsion motor (ProMo) is the main goal of this research paper.

Limitations, such as energy storage development [3] and electric motor performance [4], are hindering the progress of propulsion electrification, ranging from small unmanned aircraft and drones to larger twin-aisle aircraft [5]-[7]. Technological maturity is such that having demonstrated taxilike applications for one to four passengers [8], [9], this paper aims to move a step forward to fill the gap of the eight to twelve passenger aircraft, with a power requirement of less than 600 $\mathrm{kW}$, thus, providing a steppingstone for even larger aircraft. Building the confidence for motor designs for this size of aircraft will enable even more projects such as E-Fan and Zunum Aero [10], [11].

This paper deals with the design improvement of an existing ProMo intended for propelling a twelve-passenger aircraft [12]. This is achieved through implementing a restriction to the operating conditions such as constraining the phase current to $200 \mathrm{~A} \mathrm{rms}$ and limiting the cooling system pressure drop to 2 bar, also implementing indirect winding cooling. Therefore, the new design aims at emphasising the electromagnetic (EM) and thermal characteristics of the ProMo, while maintaining a direct-drive configuration. The previous version of the ProMo is used as a reference motor and through a series of modifications, it will be used within the defined application requirements.

The paper is organised as follows: the main design requirements and boundaries are defined in Section II; the detailed design process of the ProMo is provided in Section III; in Section IV introduces the thermal management system design and a mechanical stress analyses is undertaken. Section V the full details, in terms of dimensions and performance of the finalised machine design, are elaborated upon. Finally, conclusions and future work are presented in Section V.

\section{DESIGN REQUIREMENTS AND BOUNDARIES}

This section gives the main performance indicators and design targets of the benchmark ProMo. Then it presents the new design requirements and boundaries for the new design. While the main goal of the benchmark motor study was to maximise the output power for a given mechanical envelope. The key objective of this study was to redesign the machine for the same application, but with improved, yet more restrictive, design boundaries as elaborated in this section.

The benchmark design was a 36-slot, 30-pole motor. The rated continuous output power was $750 \mathrm{~kW}$, with a rated rms

$1 \square$ This work is funded by the INNOVATIVE doctoral programme. The INNOVATIVE programme is partially funded by the Marie Curie Initial Training Networks (ITN) action (project number 665468) and partially by the Institute for Aerospace Technology (IAT) at the University of Nottingham, UK 
phase current of $325 \mathrm{~A}$ and power density of $7.5 \mathrm{~kW} / \mathrm{kg}$. This motor was optimised for high power density operation and no limits for the phase current were set. The full design development and performance is reported in [12]. However, the high current design would inherently lead to a high rating for the power converter feeding the ProMo, as well as creating high demand on the thermal management system. Certain environmental conditions are assumed to be constant such as altitude and fixed ambient temperature. The main performance requirements and boundaries for the new ProMo are summarised as follows:

- Design requirements:

$$
\begin{array}{ll}
\circ & \text { Continuous propulsion power }=550 \mathrm{~kW} \\
\circ & \text { Efficiency }>97 \% . \\
\circ & \text { Power density }>5 \mathrm{~kW} / \mathrm{kg} . \\
\circ & \text { Rated speed }=2000 \mathrm{rpm} . \\
\circ & \text { Maximum active outer diameter }=463 \mathrm{~mm} . \\
\circ & \text { Maximum active stack length }=151 \mathrm{~mm} . \\
\circ & \text { DC link voltage }=540 \mathrm{~V} . \\
\circ & \text { AC phase current }=200 \text { Arms. }
\end{array}
$$

- Design boundaries:

$$
\begin{array}{ll}
\circ & \text { Maximum airgap thickness }=2 \mathrm{~mm} . \\
\circ & \text { Maximum PM thickness }=20 \mathrm{~mm} . \\
\circ & \text { Maximum axial magnet segments }=25 \text {. } \\
\circ & \text { Five stage Halbach array. } \\
\circ & \text { Ambient temperature }=40^{\circ} \mathrm{C} . \\
\circ & \text { Liquid water jacket. } \\
\circ & \text { Maximum Pressure drop }=2 \mathrm{bar} . \\
\circ & \text { Winding thermal limit }=180{ }^{\circ} \mathrm{C} . \\
\circ & \text { PM thermal limit }=350{ }^{\circ} \mathrm{C} . \\
\circ & \text { PM material is Recoma } 33 \mathrm{E} . \\
\circ & \text { Stator material is Vacoflux } 50 . \\
\circ & \text { Rotor material is } \mathrm{M} 350-50 \mathrm{~A} .
\end{array}
$$

\section{DEVElopment OF THE ProMo}

The design development proposed is based on EM FE simulation environment. Firstly, a slot/pole combination study was carried out with a detailed analysis of different winding connections. Then optimisation of the airgap thickness and PM thickness was performed, followed by the re-sizing of the motor to fully utilise the given geometrical and thermal boundaries.

\section{A. Slot/Pole combination study}

Several slot/pole combinations are reported in Table I to start the ProMo design development. The chosen designs cover a wide range of winding and pole pitch configurations which were simulated in a transient 2D FE software packages using Infologica Magnet and Motor-CAD. The main candidate selection criteria for this study are:

- High winding factor.

- High least common multiplier (LCM) of slots and poles, to ensure a low torque ripple.

- A design permitting high flexibility of winding connections.

- Multi 3-phase groups are considered to increase the fault-tolerance and decrease the current rating for a better exploitation of the power electronics.

The results summary is shown in Fig. 1. Following the design requirements, the motors S60-P16, S60-P20, and S72P22 are the most optimal designs. The motor with the 72 slots and 22 poles was selected for further analysis, as it had the highest efficiency, $4.7 \mathrm{~kW} / \mathrm{kg}$ in power density, low torque ripple of less than $2 \%$ and second highest output power.

TABLE I

INVESTIGATED SLOT/POLE COMBINATIONS

\begin{tabular}{ccccccc}
\hline Slots & Poles & $\begin{array}{c}\text { Coil } \\
\text { span }\end{array}$ & $\begin{array}{c}\text { Winding } \\
\text { factor }\end{array}$ & LCM & $\begin{array}{c}\text { Possible } \\
\text { 3-Phase } \\
\text { Groups }\end{array}$ & $\begin{array}{c}\text { Freq. } \\
\text { (Hz) }\end{array}$ \\
\hline 36 & 12 & 3 & 1.000 & 36 & $1,2,3,4$ & 200.0 \\
48 & 16 & 3 & 1.000 & 48 & $1,2,4$ & 266.7 \\
60 & 16 & 3 & 0.951 & 240 & $1,2,4$ & 266.7 \\
18 & 16 & 1 & 0.945 & 144 & $1,2,3$ & 266.7 \\
54 & 18 & 3 & 1.000 & 54 & $1,2,3$ & 300.0 \\
24 & 20 & 1 & 0.966 & 120 & $1,2,4$ & 333.3 \\
60 & 20 & 3 & 1.000 & 60 & $1,2,4$ & 333.3 \\
18 & 20 & 1 & 0.945 & 180 & $1,2,3$ & 333.3 \\
72 & 22 & 3 & 0.945 & 792 & $1,2,3,4$ & 366.7 \\
27 & 24 & 1 & 0.945 & 216 & 1,3 & 400.0 \\
27 & 30 & 1 & 0.945 & 270 & 1,3 & 500.0 \\
36 & 30 & 1 & 0.966 & 180 & $1,2,3,4$ & 500.0 \\
\hline
\end{tabular}

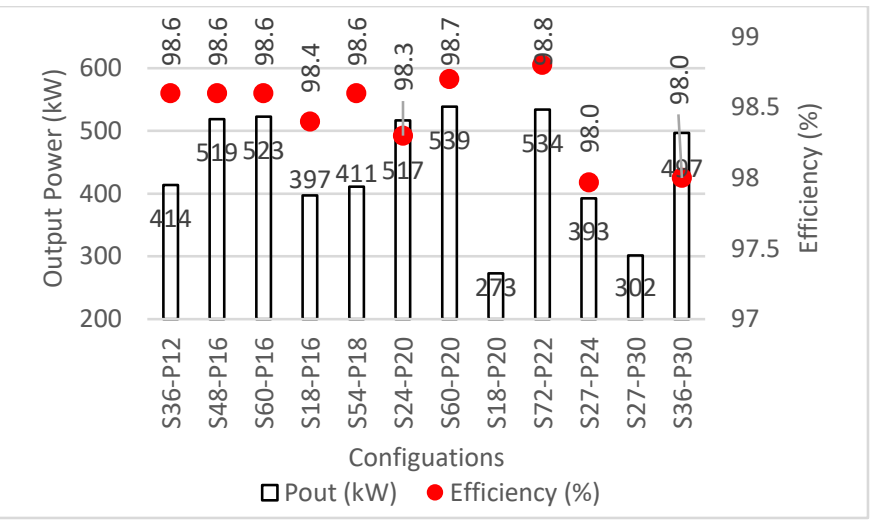

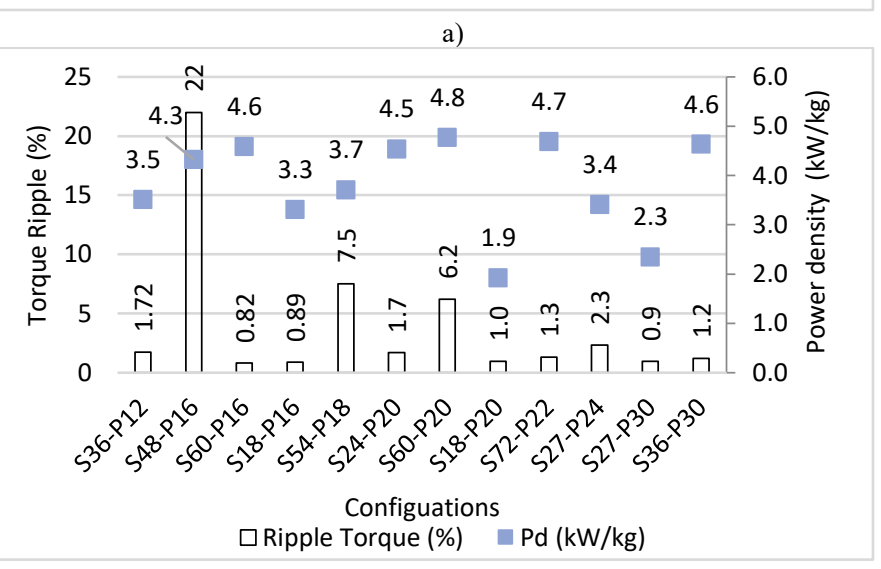

b)

Fig. 1: Slot/Pole trade-off study results: a) output power and efficiency; b) torque ripple.

B. Winding configuration, electrical loading, and PM-toairgap ratio study

This study explores, in further depth, the effect of winding configuration and current loading, as well as the airgap thickness and PM thickness for the selected design. The nominated 72-slot and 22-pole motor had a preliminary design with a $2 \mathrm{~mm}$ airgap, $20 \mathrm{~mm}$ PM thickness and four sets of windings carrying $200 \mathrm{~A}$ rms current. In this preliminary study, only three combinations of airgap thickness to PM thickness ratios were considered: $2 / 20,1 / 20,1 / 15$. Whereas, the winding configurations range from 1 to 4 sets of 3 -phase windings, and the current is fixed at $200 \mathrm{~A} \mathrm{rms}$ and then adjusted to account for the accumulated single-phase winding loading. 
The summary of the design variations and results are reported in Table II. There is an expected proportional relationship between the output torque and the number of three-phase winding sets. The performance of the motor is also improved when the PM thickness is reduced from $20 \mathrm{~mm}$ to $15 \mathrm{~mm}$ at 1 mm thickness of the airgap and $200 \mathrm{~A} \mathrm{rms}$, as the power density increases, and the PM weight decreases. Therefore, the selection of the design with four sets of three-phase windings is verified as the optimal design at this point of study. Yet, the ratio between the magnet thickness and the airgap thickness deserves a more detailed analysis which will be the focal point of the next subsection.

TABLE II

WINDING CONFIGURATION AND ELECTRICAL LOADING STUDY FINDINGS

\begin{tabular}{|c|c|c|c|c|c|c|c|}
\hline $\begin{array}{c}3 \Phi \\
\text { Groups }\end{array}$ & $\begin{array}{l}\text { I } \Phi \\
\max . \\
(\mathrm{A})\end{array}$ & $\begin{array}{l}\text { Airgap } \\
\text { thickness } \\
(\mathrm{mm}) / \\
\text { PM } \\
\text { thickness } \\
(\mathrm{mm})\end{array}$ & $\begin{array}{l}\text { Avg. } \\
\text { Torque } \\
\text { (Nm) }\end{array}$ & $\begin{array}{c}\text { Torque } \\
\text { Ripple } \\
(\%)\end{array}$ & $\begin{array}{l}\text { Pout } \\
(\mathrm{kW})\end{array}$ & $\begin{array}{c}\text { Effici } \\
\text { ency } \\
(\%)\end{array}$ & $\begin{array}{c}\mathrm{Pd} \\
(\mathrm{kW} / \\
\mathrm{kg})\end{array}$ \\
\hline \multirow{3}{*}{$1 \mathrm{G}$} & \multirow{3}{*}{200} & $2 / 20$ & 626 & 5.06 & 131 & 97.57 & 1.15 \\
\hline & & $1 / 20$ & 643 & 8.3 & 135 & 97.46 & 1.17 \\
\hline & & $1 / 15$ & 625 & 6 & 131 & 97.7 & 1.2 \\
\hline \multirow{3}{*}{$2 \mathrm{G}$} & \multirow{3}{*}{200} & $2 / 20$ & 1291 & 7.07 & 270 & 23.6 & 2.41 \\
\hline & & $1 / 20$ & 1316 & 12.8 & 276 & 98.5 & 2.44 \\
\hline & & $1 / 15$ & 1270 & 5.1 & 266 & 98.07 & 2.49 \\
\hline \multirow{3}{*}{$3 \mathrm{G}$} & \multirow{3}{*}{200} & $2 / 20$ & 1965 & 2.2 & 411 & 98.3 & 3.64 \\
\hline & & $1 / 20$ & 2017 & 3.2 & 422 & 98.91 & 3.67 \\
\hline & & $1 / 15$ & 1948 & 2.4 & 408 & 98.76 & 3.74 \\
\hline \multirow{3}{*}{$4 \mathrm{G}$} & \multirow{3}{*}{200} & $2 / 20$ & 2555 & 0.6 & 535 & 98.8 & 4.78 \\
\hline & & $1 / 20$ & 2615 & 2.3 & 547 & 98.7 & 4.84 \\
\hline & & $1 / 15$ & 2513 & 2.3 & 526 & 98.54 & 4.92 \\
\hline \multirow{3}{*}{$1 \mathrm{G}$} & \multirow{3}{*}{800} & $2 / 20$ & 2482 & 3.9 & 520 & 98.6 & 4.56 \\
\hline & & $1 / 20$ & 2540 & 5 & 532 & 98.72 & 4.61 \\
\hline & & $1 / 15$ & 2444 & 4.2 & 512 & 98.52 & 4.7 \\
\hline \multirow{3}{*}{$2 \mathrm{G}$} & \multirow{3}{*}{400} & $2 / 20$ & 2440 & 6.9 & 510 & 98.6 & 4.55 \\
\hline & & $1 / 20$ & 2509 & 11.5 & 525 & 98.58 & 4.69 \\
\hline & & $1 / 15$ & 2378 & 5.4 & 498 & 98.38 & 4.65 \\
\hline \multirow{3}{*}{$3 \mathrm{G}$} & \multirow{3}{*}{267} & $2 / 20$ & 2586 & 2.2 & 541 & 98.4 & 4.79 \\
\hline & & $1 / 20$ & 2645 & 2 & 554 & 98.8 & 4.82 \\
\hline & & $1 / 15$ & 2547 & 2.2 & 533 & 98.6 & 4.89 \\
\hline
\end{tabular}

C. PM thickness and airgap thickness optimisation study

Finer tuning of the airgap thickness and the PM thickness is analysed. The results are summarised in Fig. 2. The output power, as shown in Fig. 2.a, increases with thicker PM and smaller airgap thicknesses, which is expected. However, the output power trend is not fully linear starting after the $15 \mathrm{~mm}$ thickness change in slope indicating start of saturation. The same observation can be noted in Fig. 2.b, where power density approaches saturation after at $14 \mathrm{~mm}$ of PM thickness for any value of the airgap thickness. Also, the gain in power density is insignificant after this point. Higher torque ripples are experienced with smaller airgap thicknesses. Nevertheless, the maximum is $1.9 \%$ at $1 \mathrm{~mm}$ as it can be observed in Fig. 2.c, so it is still deemed to be a reasonable value. To fully utilise the potential of the motors, the airgap is set at $1 \mathrm{~mm}$ and the PM thickness at $15 \mathrm{~mm}$, this can reduce the PM weight by $6 \mathrm{~kg}$.

Hence, the results in Table II are still valid in this study and the design incorporating four sets of windings is selected, with $1 \mathrm{~mm}$ of airgap thickness and PM thickness of $15 \mathrm{~mm}$. The output power is $526 \mathrm{~kW}$ in this case, which is not too far from the pre-set requirement and can be compensated with further design optimisation.

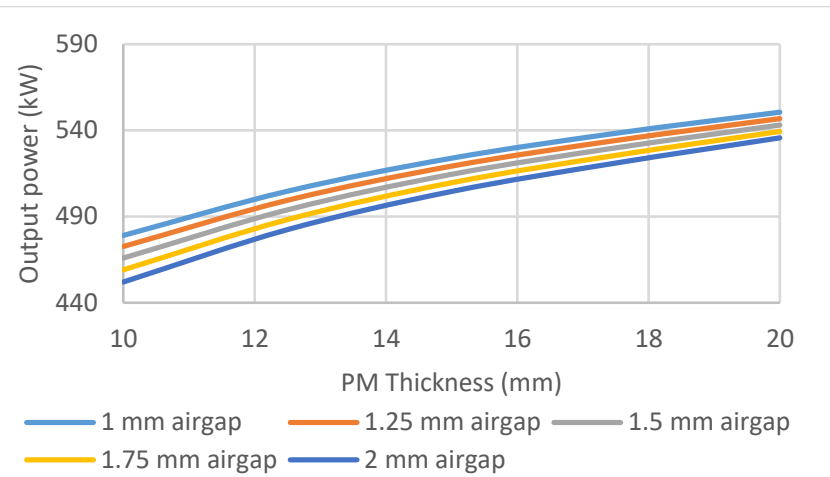

a)

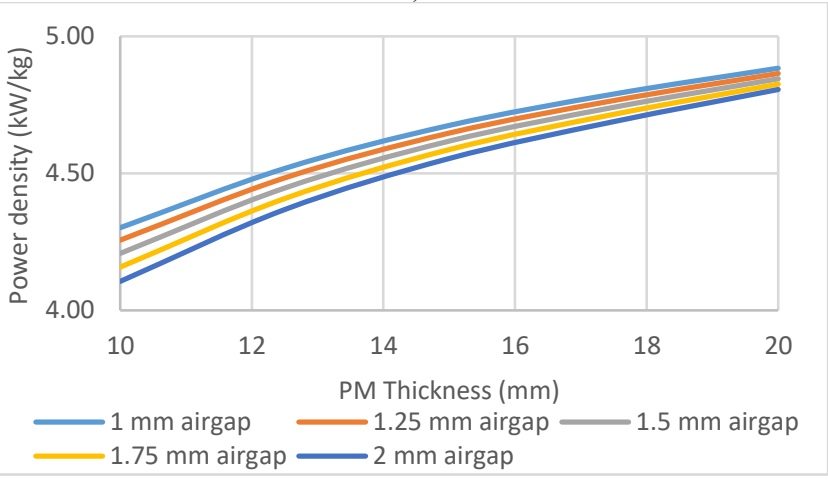

b)

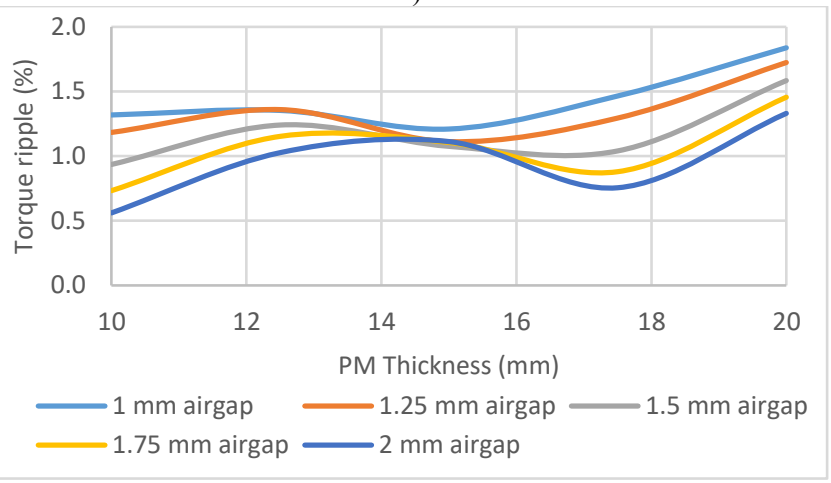

c)

Fig. 2: PM thickness and airgap study: a) output power; b) power density; c) torque ripple

\section{Resizing for maximum EM and thermal utilisation}

The thermal performance of the motor was evaluated by considering the use of a cooling liquid water jacket with a maximum pressure drop across the machine of 2 bar. The peak temperature limit of the winding is set at $180{ }^{\circ} \mathrm{C}$, and $350{ }^{\circ} \mathrm{C}$ for the magnets. For this base design, the peak temperature of the winding is $143{ }^{\circ} \mathrm{C}$. Hence, it is under-utilised in terms of thermal performance. This design is labelled as 'base' in Table III. Whereas the same design but increasing the current to 220 A rms - usually allowed by power converters for short durations. Simulation at this $10 \%$ increase of phase current, the winding reach the insulation thermal limit of $180^{\circ} \mathrm{C}$, this design is labelled as 'base_max'.

A resizing exercise is performed on this 'base' design, where stator outer diameter, stack length and split ratio were varied, which resulted in different outer volumes and referred to with unique design ID. The main aim is to fully utilise the available space in terms of EM and thermal performance, under a similar thermal management system, which will be detailed later in Section IV. Therefore, reducing the motor overall outer dimensions is also targeted to optimise the design. 
The results are listed in Table III and a selection of high performing motors are represented in Fig. 3. The design with ID number 12 - as in Table III - has the best overall performance, thus it is selected as the final design. These full design details are reported in the next section.

TABLE III

SUMMARY OF THE RESIZING STUDY RESULTS

\begin{tabular}{c|ccccccc}
$\begin{array}{c}\text { Volume } \\
(\text { Litre })\end{array}$ & $\begin{array}{c}\text { Design } \\
\text { ID }\end{array}$ & $\begin{array}{c}\text { Po } \\
(\mathrm{kW})\end{array}$ & $\begin{array}{c}\text { Pd } \\
(\mathrm{kW} / \mathrm{kg})\end{array}$ & $\begin{array}{c}\text { Efficiency } \\
(\%)\end{array}$ & $\begin{array}{c}\text { Mass } \\
(\mathrm{kg})\end{array}$ & $\begin{array}{c}\text { Cu } \\
\text { Temp. } \\
\left({ }^{\circ} \mathrm{C}\right)\end{array}$ & $\begin{array}{c}\text { Memp. } \\
\left({ }^{\circ} \mathrm{C}\right)\end{array}$ \\
\hline 12.4 & 1 & 260 & 4.8 & 97.99 & 53.9 & 184 & 122 \\
13.5 & 2 & 257 & 4.36 & 97.9 & 58.9 & 179 & 163 \\
13.5 & 3 & 343 & 5.81 & 98.3 & 59.1 & 186 & 162 \\
15.7 & 4 & 419 & 6.14 & 98.4 & 68.2 & 193 & 171 \\
17.0 & 5 & 398 & 5.03 & 98.36 & 79.2 & 173 & 176 \\
17.0 & 6 & 457 & 6.14 & 98.43 & 74.4 & 174 & 120 \\
17.0 & 7 & 405 & 5.91 & 98.38 & 68.5 & 174 & 173 \\
17.0 & 8 & 399 & 6.19 & 98.33 & 64.5 & 180 & 178 \\
19.0 & 9 & 488 & 6.1 & 98.55 & 80.7 & 172 & 121 \\
19.4 & 10 & 494 & 6.03 & 98.55 & 82.1 & 187 & 163 \\
21.1 & 11 & 523 & 5.24 & 98.63 & 101.1 & 172 & 174 \\
\hline $\mathbf{2 1 . 1}$ & $\mathbf{1 2}$ & $\mathbf{5 7 0}$ & $\mathbf{6 . 3 8}$ & $\mathbf{9 8 . 5 9}$ & $\mathbf{8 9 . 3}$ & $\mathbf{1 7 3}$ & $\mathbf{1 2 3}$ \\
\hline 21.1 & 13 & 532 & 6.27 & 98.58 & 84.9 & 174 & 177 \\
21.1 & 14 & 514 & 6.51 & 98.5 & 79.0 & 186 & 190 \\
23.3 & 15 & 559 & 6.07 & 98.59 & 92.2 & 173 & 187 \\
23.3 & 16 & 587 & 5.85 & 98.62 & 100.4 & 184 & 207 \\
23.3 & 17 & 562 & 6.45 & 98.53 & 87.2 & 184 & 200 \\
25.4 & Base & 523 & 4.92 & 98.64 & 106.0 & 143 & 177 \\
25.4 & Base_max & 602 & 5.67 & 98.6 & 106.0 & 177 & 198
\end{tabular}

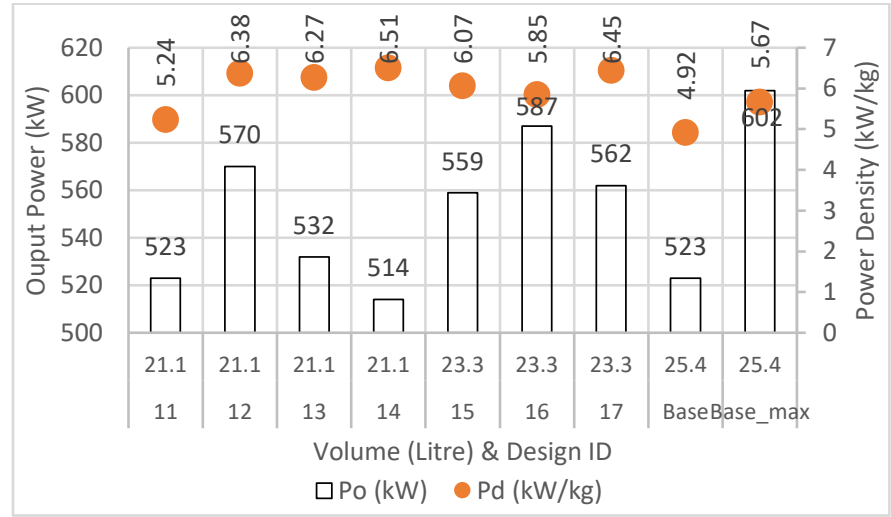

Fig. 3: Resizing study results.

\section{Thermal MANAGEMENT System Design AND MECHANICAL ANALYSIS}

This section discusses the proposed thermal management system. The machinal stress analysis is also included for the motor roto.

\section{A. Thermal Management}

The highest losses are generated in the stator core and windings. The AC winding losses are set to be zero, as sufficiently thin strands are used and are assumed to ensure that skin and proximity effects [13] may be neglected in the range of frequencies - under $400 \mathrm{~Hz}$ - considered in this design. Direct winding cooling was not considered for this application. The flooded rotor was not selected due to high windage losses and a flooded stator arrangement was not considered, due to manufacturing and maintenance complexities. Therefore, a spiral shaped liquid ethylene glycol and water (EGW) jacket around the stator core was included within the $10 \mathrm{~mm}$ thickness of the housing. A variation to this design is also studied by considering the addition of axial rotor air cooling ducts.

As shown in Fig. 4, the cooling system consists of two parallel spiral EGW paths. The pressure drop across the machine is less than 2 bar, and the total flow rate is $221 / \mathrm{min}$. The average winding temperature at the steady-state condition is $172{ }^{\circ} \mathrm{C}$, where the insulation temperature class limit is 180 ${ }^{\circ} \mathrm{C}$. The main parameters for this cooling spiral jacket are listed in Table IV. The temperatures of individual motor components at the fully loaded condition, are shown in Table $\mathrm{V}$ labelled in column 'WJC'. The thermal analysis was solved using the commercial Lumped Parameter Thermal Network software, Motor-CAD V13. For this WJC only case, the winding operates near its thermal limit, but the PM peak temperature of $218^{\circ} \mathrm{C}$ is significantly below its thermal limit of $350{ }^{\circ} \mathrm{C}$.

Designing for lower temperatures is possible by a modified thermal management system approach, consisting of adding an air ventilation system of $30 \mathrm{~mm}$ diameter axial 12 holes through the rotor, with a pitch circle diameter of $220 \mathrm{~mm}$ from the axis of rotation, as depicted in Fig. 5. A flow rate of $150 \mathrm{~m}^{3} / \mathrm{hr}$ creates a pressure drop of $100 \mathrm{~Pa}$ across the machine. After this modification, the average winding temperature dropped by $10 \%$ to $155^{\circ} \mathrm{C}$ and magnet temperature reduced by $29 \%$ to $154{ }^{\circ} \mathrm{C}$, as listed in Table VI column labelled as 'WJC \& RD'. This increased thermal margin would allow for higher or longer temporary overload or improved lifetime of the motor.

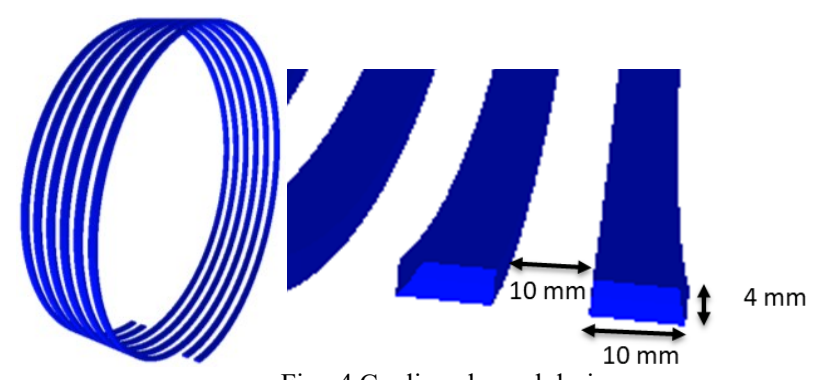

Fig. 4 Cooling channel design.

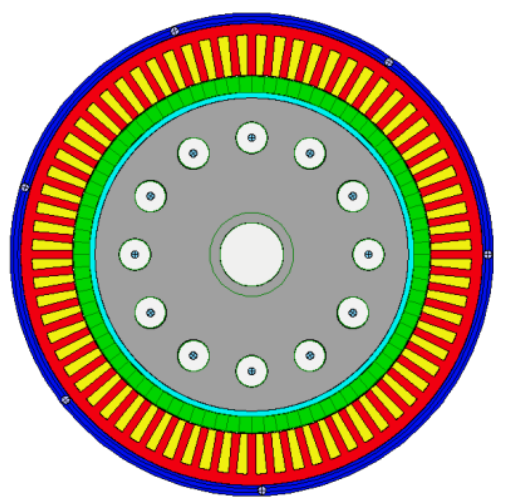

Fig. 5: Modified rotor design for improved thermal performance TABLE IV

Thermal Management System Parameters

\begin{tabular}{c|c} 
Parameter & Value \\
\hline Water jacket height $(\mathrm{mm})$ & 4 \\
Water jacket width $(\mathrm{mm})$ & 10 \\
Water jacket spacing $(\mathrm{mm})$ & 10 \\
Water jacket to housing $(\mathrm{mm})$ & 3 \\
Flow rate $(1 / \mathrm{min})$ & 22 \\
Pressure drop (bar) & 1.97 \\
Cooling parallel paths & 2 \\
Cooling fluid & EGW50/50
\end{tabular}


TABLE V

Thermal Management System Parameter Material/Part

Housing/ Aluminium

Stator/ Vacoflux 50

Wire insulation

Impregnation

Slot wedge

Slot liner

Rotor/ M350-50A

Magnet/ Recoma

TABLE VI

Motor Parts Maximum Temperature At Steady State

\begin{tabular}{c|cc} 
Parameter & $\begin{array}{c}\text { WJC - } \\
\text { Temp. }\left({ }^{\circ} \mathrm{C}\right)\end{array}$ & $\begin{array}{c}\text { WJC \& RD - } \\
\text { Temp. }\left({ }^{\circ} \mathrm{C}\right)\end{array}$ \\
\hline Ambient & 40 & 40 \\
Housing & 49 & 49 \\
Active winding (maximum) & 180 & 167 \\
Active winding (Average) & 172 & 155 \\
Magnet & 218 & 154 \\
Stator laminations & 103 & 95 \\
Rotor laminations & 216 & 149 \\
Shaft & 209 & 124 \\
Cooling fluid (inlet/outlet) & $40 / 47$ & $40 / 46$
\end{tabular}

\section{B. Mechanical Analysis}

The mechanical performance of the rotor with the cooling holes was executed using the ANSYS Mechanical 2020 R2 FEA software package. The mechanical performance of the rotor was simulated at a $25 \%$ overspeed at $2500 \mathrm{rpm}$. The rotor lamination and magnet regions were simulated with the cooling ducts featured, as shown in Fig. 6 . The yield strength of the rotor M350-50A material is $305 \mathrm{MPa}$. The maximum stress at the rotor was $15 \mathrm{MPa}$, hence the safety factor, at the overspeed rotational condition, is above 20 . This demonstrates that the cooling ducts do not have an adverse effect on the machine's mechanical integrity.

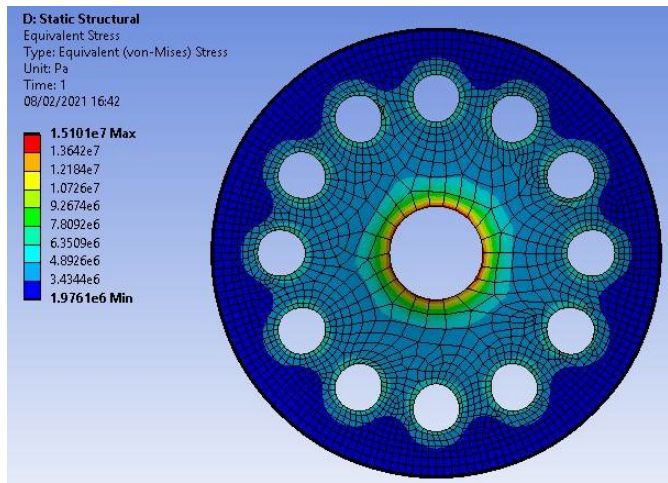

Fig. 6: Mechanical analysis.

\section{Final EleCtromagnetic DESIGN}

In this section, the final design of the motor is presented in terms of EM performance, winding connection and main design features and dimensions.

The mesh and the flux density map are shown in Fig. 7 a) and b) respectively. The 'Vacoflux 50' material has a saturation at $2.25 \mathrm{~T}$, which allows flux density in the stator to be increased significantly, providing more area to accommodate the copper. The materials are defined in the design boundaries section listed in Section II.

The main performance indicators and motor dimensions are listed in Table IV. The stack length is $9 \mathrm{~mm}$ shorter, and the outer diameter is $435 \mathrm{~mm}$ compared to the $463 \mathrm{~mm}$ of the original permissible space. This yields the significant reduction in a motor volume of $17 \%$, below the maximum space envelope requirement. The motor also incorporates an open slot design, for more simple manufacturing and winding procedures, yet the torque ripple is only limited at $0.4 \%$. At $2000 \mathrm{rpm}$ the output power is $555 \mathrm{~kW}$, thus satisfying the power requirement.

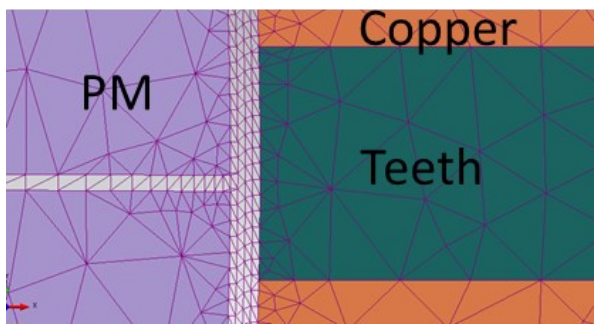

a)

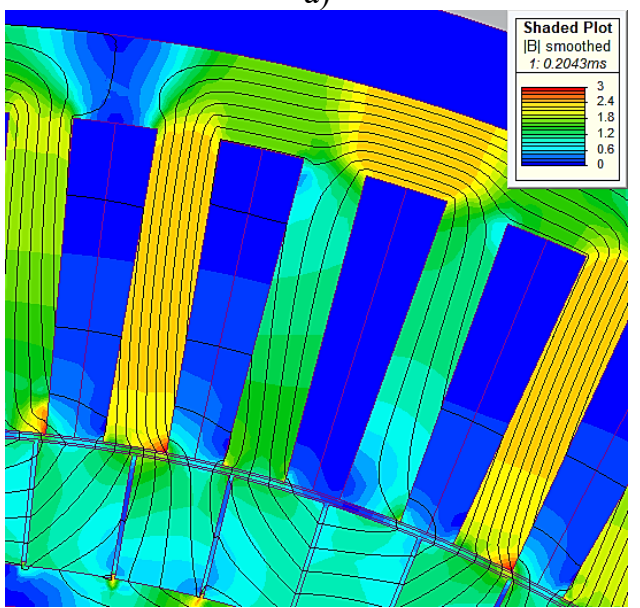

Fig. 7: FE model: a) detail of the mesh used and b) flux lines and field map.

TABLE IV

\begin{tabular}{c|c||c|c}
\multicolumn{4}{c}{ ProMo Main Design Features and Parameters } \\
Parameter & Value & Parameter & Value \\
\hline Slots/Poles & $72 / 22$ & Average Torque $(\mathrm{Nm})$ & 2654.1 \\
Magnet thickness (mm) & 15 & Torque Ripple $(\%)$ & 0.4 \\
Airgap thickness (mm) & 1 & Output Power (kW) & 555 \\
Housing Dia (mm) & 455 & Power Density (kW/kg) & 6.12 \\
Stator Lam Dia (mm) & 435 & Efficiency (\%) & 98.5 \\
Stator Bore (mm) & 338 & Stator Losses (W) & 991 \\
Rotor Inner Dia (mm) & 296 & PM Losses (W) & 2796 \\
Tooth Width (mm) & 7.8 & Cu Losses DC (W) & 4280 \\
Slot Depth (mm) & 38 & Rotor losses (W) & 140 \\
Tooth tips depth (mm) & 0 & Total losses (W) & 8208 \\
Slot opening (mm) & 7 & I_ph_rms (I) & 220 \\
Axial Length (mm) & 142 & Jrms (A/mm2) & 9.5 \\
Number PM segments & 25 & Number of Turns & 4 \\
Weight (kg) & 90.8 & Number of 3- $\Phi$ Groups & 4
\end{tabular}

As stated earlier, the motor has four sets of three-phase windings. The layout of the phasor vectors is demonstrated in Fig. 8. The sets $(\mathrm{G} 1: \mathrm{G} 4)$ voltage vectors are identified as follows: G1: 1, 2, 3. G2: 4, 5, 6. G3: 7, 8, 9. G4: 10, 11, 12. The winding spacial distribution implemented in the FEM model is displayed in Fig. 9. The displacement between each phase group is $30^{\circ}$ such as between vector 1 and 4 , and a $120^{\circ}$ - as in between vector 1 and 2 - phasor displacement in the same group is applied. The phase voltage waveform at full load and 2000 rpm for the full 12 phases in shown in Fig. 10. The torque waveform is plotted in Fig. 11. The torque ripple absolute value is less than $10 \mathrm{Nm}$ over the full load torque of $2652 \mathrm{Nm}$, accounting for only $0.4 \%$. 


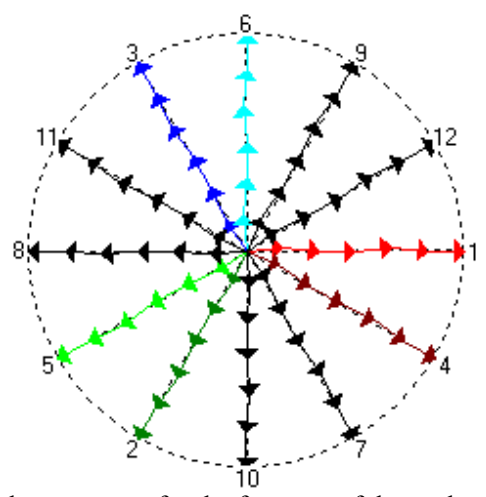

Fig. 8: Voltage vectors for the four sets of three-phase windings.

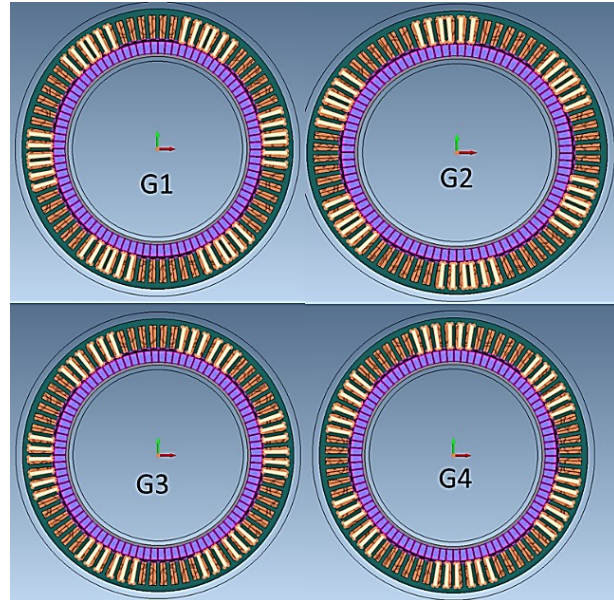

Fig. 9: Winding arrangement.

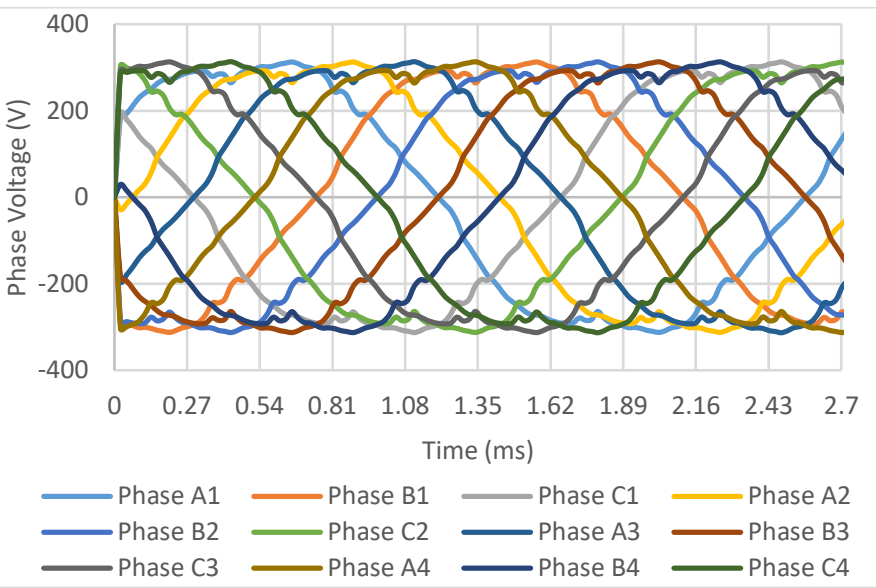

Fig. 10: Phase voltage waveforms.

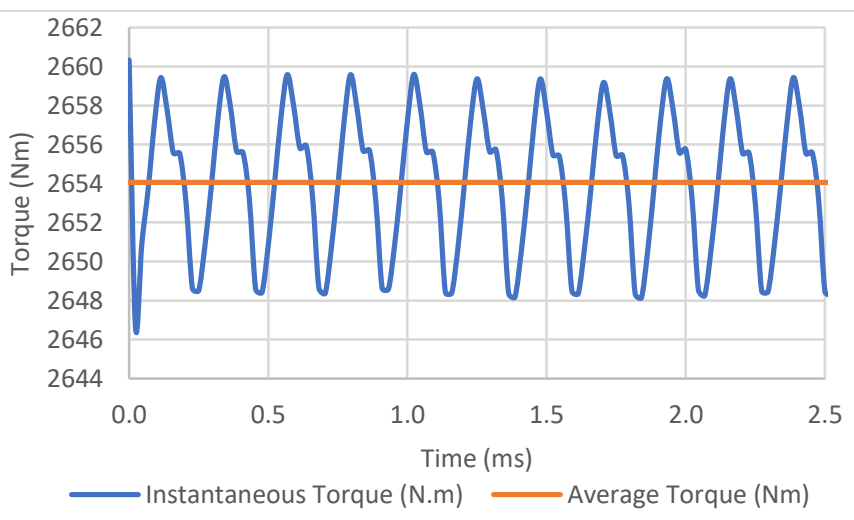

Fig. 11: Full load torque waveform

\section{COnClusions}

The design of an aircraft propulsion motor has been presented in this paper by modifying and improving an existing reference electrical machine for a commercial 8-12 passenger aircraft, such as Cessna Caravan. Stricter design thermal and electrical boundaries and ambitious performance targets were set. The required output power of $550 \mathrm{~kW}$ was achieved, very low torque ripple of $0.4 \%$ is also reached without the need for skewing the rotor magnets or the stator slots. Compared to the previous design, this motor has double the slots and 8 poles lower (from 30 to 22), hence, for the same operating speed it has a lower fundamental frequency. Thus, it inherently reduces the losses in the stator and rotor cores, PM surface and reduces the load on the power converters.

The designed water jacket cooling system manages to keep the motor temperatures within the thermal limits, without direct winding cooling or shaft liquid cooling. Additionally, the proposed motor is $17 \%$ smaller in volume, thus enhancing the integration with the aircraft propeller system. The magnets' thickness is reduced by $5 \mathrm{~mm}$, thus reducing their overall weight and purchase costs. The stator slots are kept open to ease the machining, winding and future maintenance processes.

\section{REFERENCES}

[1] A. S. Gohardani, G. Doulgeris, and R. Singh, "Challenges of future aircraft propulsion: A review of distributed propulsion technology and its potential application for the all electric commercial aircraft," Prog. Aerosp. Sci., vol. 47, no. 5, pp. 369-391, Jul. 2011, doi: 10.1016/j.paerosci.2010.09.001.

[2] A. Hebala, S. Nuzzo, P. H. Connor, P. Giangrande, C. Gerada, and M. Galea, "PM Halbach Arrays in Motors: Loss Reduction and Performance Improvements," in 2020 23rd International Conference on Electrical Machines and Systems (ICEMS), Nov. 2020, pp. 710 715, doi: 10.23919/ICEMS50442.2020.9291234.

[3] A. Recalde et al., "Energy Storage System Selection for Optimal Fuel Consumption of Aircraft Hybrid Electric Taxiing Systems," IEEE Trans. Transp. Electrif., pp. 1-18, 2020, doi: 10.1109/TTE.2020.3039759.

[4] A. El-Refaie, "Toward a Sustainable More Electrified Future: The Role of Electrical Machines and Drives," IEEE Electrif. Mag., vol. 7, no. 1, pp. 49-59, 2019, doi: 10.1109/MELE.2018.2889551.

[5] A. El-Refaie and M. Osama, "High specific power electrical machines: A system perspective," 2017 20th Int. Conf. Electr. Mach. Syst. ICEMS 2017, 2017, doi: 10.1109/ICEMS.2017.8055931.

[6] M. Galea, Z. Xu, C. Tighe, T. Hamiti, C. Gerada, and S. Pickering, "Development of an aircraft wheel actuator for green taxiing," Proc. - 2014 Int. Conf. Electr. Mach. ICEM 2014, pp. 2492-2498, 2014, doi: 10.1109/ICELMACH.2014.6960537.

[7] X. Zhang and K. S. Haran, "High-specific-power electric machines for electrified transportation applications-technology options," $E C C E$ 2016 - IEEE Energy Convers. Congr. Expo. Proc., pp. 1-8, 2016, doi: 10.1109/ECCE.2016.7855164.

[8] S. Downing, "6 electric aviation companies to watch," 2019. https://www.greenbiz.com/article/6-electric-aviation-companieswatch (accessed Oct. 30, 2019).

[9] M. Henke et al., "Challenges and opportunities of very light highperformance electric drives for aviation," Energies, vol. 11, no. 2 , 2018, doi: 10.3390/en11020344.

[10] “Zunum Aero." https://zunum.aero/ (accessed Oct. 30, 2019).

[11] "A giant leap towards zero-emission flight." https://www.airbus.com/innovation/future-technology/electricflight/e-fan-x.html (accessed Oct. 30, 2019).

[12] A. Hebala et al., "Feasibility Design Study of High-Performance, High-Power-Density Propulsion Motor for Middle-Range Electric Aircraft," IEEE Int. Symp. Ind. Electron., vol. 2020-June, no. 665468, pp. 300-306, 2020, doi: 10.1109/ISIE45063.2020.9152551. Q. H. Quadri, S. Nuzzo, C. Gerada, and M. Galea, "Analysis and Modelling of High Frequency Effects on Synchronous Generator's Armature Conductors," IEEE Int. Symp. Ind. Electron., vol. 2020June, pp. 253-258, 2020, doi: 10.1109/ISIE45063.2020.9152456. 